Work(ing) Artefacts: Tools of the Trade, Totems or Trophies?

\author{
Tom Baum $^{\mathrm{a}} \quad$ Richard Robinson $^{\mathrm{b}}$
}

${ }^{a}$ University of Strathclyde

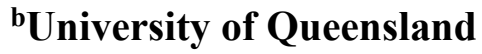




\section{Work(ing) Artefacts: Tools of the Trade, Totems or Trophies?}

\section{Abstract}

Do workplace artefacts have utility, for their custodians, beyond the workplace context? A new materiality perspective allowed the conversation to move beyond the parameters of the organisation and into the private spheres of both practicing and retired para-professionals. In this study of chefs, we discover the deliberate acquisition of occupational artefacts beyond their organisational utility. These artefacts betray a post-occupational identify deeply revelatory of materiality. We ask in what ways are these artefacts symbolic, or totemic? Findings provide fresh insights into how artefacts are mobilised as reverent 'working' objects, as totems, and trophies for nostalgia. This facilitates reflections on how work was or ought to be and so in turn who or 'what I am' or 'who I was'. Theoretically, this enables us to extend the nexus of materiality and work and materiality and everyday life over both time and place.

\section{Key words:}

Artefacts, materiality, agency, nostalgia, chefs, occupational culture/community 


\section{Introduction}

Treatment of workplace artefacts in the literature considers the meanings attached to them, their instrumentality (Bechky, 2003), how they impact organisational efficiency (Kaghan and Lounsbury, 2006), impose on work procedures (Eriksson-Zetterquist, Lindberg and Styhre, 2009) and their aesthetisation (Chugh and Hancock, 2009; Taylor, 2002).

Contemporary discourses on work however, have begun to consider the material as it relates to process and practice (Jarzabkowski, Spee and Smets, 2013). This is salient in the context of this paper and the evident attachment which chefs attribute to their artefacts in this study. Most chefs will have learnt about the processes of kitchen work and their particular occupational culture through broadly common institutional (college) and workplace exposure (Pratten, 2003) and this, in turn, helps to shape the common perceptions they hold of the artefacts with which they practice and value. There is little argument that cookery is material labour but, at the same time, what is produced is ephemeral and fleeting. However, the culinary occupation is rich with the permanent materiality that marks out occupational boundaries, the materiality of the objects that the craftsman and creative worker uses to produce work and the objects that record and reify work (Latour, 1992). Accordingly, this article appropriates a broader posture, one less concerned with understanding occupational artefacts as instruments in the management of workers within organisations, but more focused on their ability to reveal experiences, identity and values in the workplace and beyond into the private sphere, mobilising shared occupational culture and community (cf Sandiford \& Seymour, 2007). In particular, artefacts that are held by chefs who participated in this study are considered as agents for nostalgia: as symbols of workplaces, as signifiers of an (idealised) occupation and as the custodians of postoccupational identity and memories. Thus, this investigation extends the boundaries of extant literature to consider the meanings and functionalities of occupational artefacts in the 
workplace and then, as they are collected and repurposed, within personal spaces, outside of work, in the home and into retirement. In so doing the question is raised as to whether these artefacts are simply tools of the trade (Riemer, 1977) or (symbolic) totems, or do they constitute more significant occupational trophies, emblematic of group membership even beyond context, of what they do and who they are? Indeed, Reich and Hager (2014:424-5) argue that artefacts, in and of themselves, influence how we perceive the nature and import of work, and our occupational community, noting that this is dependent on how "diverse human actors and the material world (including non-human objects such as technologies)" pan out in the workplace. By addressing the role of artefacts in chefs' working lives and beyond into retirement, this study adds hitherto neglected temporal and spatial dimensions to our understanding of the meaning attached to occupational artefacts.

In undertaking this study, we chose not to start with theoretical preconceptions about the meaning of the artefacts that we explored with our chef respondents, rather we let our data speak to us once we had assembled responses from all participants. This led us consider the utility of new materialism as a theoretical vehicle with which to engage with our findings, drawing on the antecedent influences of actor network theory (ANT) (Latour, 1987; Garrety, 1997). Latour (1992) explains the clear role of artefacts within ANT in terms of their influence on the socio-technical environment within which we and they play a role. Griswold, Mangione and McDonnell (2013:360) clarify this further in considering "the mediating role objects and environments play in meaning-making". As a consequence of this journey, new materialism features strongly in the discussion we pursue in interpreting data and allows us to reach unexpected but valuable conclusions.

Artefacts take many forms. In this article, in order to reduce complexity, the focus is on material occupational artefacts while acknowledging that workplace titles, language, gestures and behaviours have traditionally been of considerable importance to 
anthropologists and other cultural studies scholars (Geertz, 1973). The distinctive hat or toque, the white uniform and chequered trousers of the chef, her/ his honorific titular greeting as 'Chef' (which may be retained, after retirement, as a way of preserving status and identity), alongside the tools of their trade - knives, chopping boards and pots and pans - are also readily associated. These artefacts are clear indicators or symbols of master craftsmanship, or professional status, and are worn and used with pride by those within the chef community, although sometimes not without a degree of naivety as Andersen (2004:2) reflects; "As I made my way up through the hierarchy of cooks, I discovered hidden symbols, meanings and signs in the way chefs and cooks dress". A suite of material artefacts, largely obscured from the public eye, for example menus, cookbooks and other such resources (cf Leschziner, 2007; Stewart, 2016) are axiomatic to the identity of chefs and are revealed in these data.

This study is undergirded by two interconnected bodies of knowledge. The first is located within the organisational behaviour and occupational culture literature and, in particular, focuses on the notion of identity and occupational communities. The second, naturally entangled with the first, draws on the notion of occupational, vocational or professional symbols and, in particular, the physical artefacts that portray such symbolism, both within the occupational community and in wider society.

This paper is organised as follows. We firstly engage with the literature on occupational culture and community as it relates to identity, and occupational artefacts, with a particular focus on the workplace environment of the chef. We then explain our methodological approach before reporting the findings of this qualitative study. Finally, the outcomes of the study are discussed in terms of their implications for emergent theory in the form of new materialism and our wider understanding of occupational communities. 


\section{Occupational Culture, Community and Identity}

A sense of identity is at the heart of the notion of the occupational community, in the sense that members of such communities share this sense of belongingness and a common set of cultural norms (Fraher and Gabriel, 2014). Theoretical understandings of identity have evolved in a number of discrete but related directions, for example through social world theory (Elkjaer and Huysman, 2008) and social identity theory (Tajfel, 1974; Turner, 1975), which aspire to explain leisure and organisational belongingness. We however, appropriate an occupational culture and community lens to explore identity, thus seeking to enable and give voice to the lived experiences of chefs. Salaman (1974) defines an occupational community as existing when people who are members of the same occupation, or who work together, have some sort of common life and are, to some extent, separate from the rest of society. As such, self-image is founded on an occupational role, which is shared and valued by a community and perpetuated through a formalised training and workplace socialisation process, whereby the values and behaviours of a work group are inculcated (cf Palmer Cooper and Burns, 2010; Cooper, Giousmpasoglou and Marinakou, 2017 re chefs).

There are many features of a shared occupational community, or culture, which differentiate them from other occupations but are also used within the community to forge identity, hierarchies, inclusions and exclusions. Salaman (1974) suggests that members of occupational communities build their lives around work, making friends of their work colleagues and having work-based and work-originating leisure interests (see also Guerrier and Adib, 2003). However, the nature of hospitality work, where there are clear boundaries between front-of-house (customer facing) and back-of-house employees, may lead to a stronger sense of identification with a work role, or occupation, than to a particular employer or organisational culture. 
Profiling the identity of chefs, as a sub-set within commercial hospitality, is a complex proposition when considering competing occupational rhetoric (Fine, 1996). These may generate competing discourses which materiality helps shape (Meisenbach, 2008). On the one hand, there is the narrative of the master craftsperson, or artisan, who takes pride in practising an extensive repertoire of technical skills (Zopiatis, 2010). Extending this dimension of identity, creativity is considered to also be a key occupational sensibility, both in adaptive and innovative contexts, expressed, for example, in experimentation (Peterson and Birg, 1988; Robinson \& Beesley, 2010). Cooper et al. (2017) address the social structures and processes which underpin the creation and maintenance of the occupational identity and culture of chefs, focusing on rights and rituals in the workplace, including bullying and violence, as dimensions of the inculcation of newcomers into the culture of Michelin starred restaurants (cf Burrow, Smith and Yakinthou, 2015). Finally, there is the rhetoric pertaining to the managerial professional. The key dimensions of this identity include professionalism and passion (Cullen, 2005), the businessperson (Fine, 1996), moral integrity (Middleton, 2000) and a service orientation (Timo, 1993). These contribute to administrative, organisational and leadership qualities (Harrington, 2005) and the ability to pass these on through teaching, both informal socialisation and formal instruction (Pratten 2003).

A paradox when considering the occupational identity of chefs is the tension between marginality and celebrity. Chefs have often been profiled as being part of a marginalised occupation and Salaman (1974) specifically comments on how marginality can play a role in the formation of an occupational community. Or, as Sandiford and Seymour (2007:211) put it, "marginality is the sense possessed by those in an occupational group that their status is misunderstood or undervalued by those outside the occupation", arguably an apt descriptor for many chefs. Themes such as violence in the kitchen (e.g. Burrows et al, 2015) and deviant behaviour (Harris and Ogbanna, 2002; Robinson, 2008) resonate in the chef literature. One 
such example of deviance, of significant importance to this study, is the systematic rejection of artefacts. As Taylor and Forte (2008) note, one of the barriers to the implementation of food safety programs in professional kitchens is that the imposition of associated artefacts (temperature probes, cleaning schedules, colour coded equipment etc) challenge rather than complement the chef's art as well as their status and skillsets.

Chefs share their own world-view, together with unusual customs, rituals and practices that define them as a tribe, but are not impervious to how they are represented in the media (Steno \& Friche, 2015). Unsocial working hours contribute to their exclusion from 'normal' social interaction and their subsequent deep commitment to their colleagues, or what Bourdain (2000:56) elaborates to be "blind, near-fanatical loyalty ... under battlefield conditions". These myriad dimensions of identify, complex and even contradictory, contribute to a multi-faceted occupational culture, in which chefs mobilise various rhetoric instrumentally dependent upon situation and context (Fine, 1996; Robinson, Solnet \& Breakey, 2016).

Yet no literature to date directly investigates the physical artefacts, as opposed to behavioural characteristics, which contribute to a strong, arguably global, community of chefs bound by a shared understanding of occupational artefacts. What is important to note here is that this community of practice goes beyond the specificities of the workplace to include non-working and post-working engagement with these artefacts within personal space (cf Nippert-Eng, 1996) and this is a core concern of our subsequent discussion in this article. While the boundary work of objects mediating the home-work nexus has been explored in the literature (cf Nippert-Eng, 1996), we have not found literature that speaks to the collection of occupational artefacts, in the manner in which athletes might collect the trophies of their past accomplishments. As Kaghan and Lounsbury (2006:272) note: 
[A] deep understanding of the manner in which artefacts come to be connected to collective mind often requires a close examination of the 'communities of practice' who are routinely involved with the artifact.

Artefacts, therefore, have a strong connection to organisational culture. Geertz (1973) contends that such symbols are "vehicles of 'culture" (Ortner, 1984:129) and the study of them gives us important insights into a particular culture, in the case of our investigation, chefs. Kaghan and Lounsbury (2006:259) reinforce the cultural construction of the meaning of artefacts and how this is inextricably linked into wider organisational culture. Artefacts, like actors, are caught up in broad institutional practices and processes that provide stability and predictability over time and space. As a result, artefacts are imbued with an institutional residue that shapes how they are constructed, used, and understood.

\section{Mobilising Occupational Artefacts}

Sociological and behavioural literatures into occupational artefacts are broadly founded on the notion that objects are symbolic and convey membership and identity. Artefacts are important in an organisational context, as Rafaeli and Vilnai-Yavetz (2003:188) point out. Physical artefacts are central to the concept of organisation - IBM is Big Blue to its constituents, McDonald's is a Big Mac and Golden Arches, and Coca Cola is red cans with a white logo.

Schein (2010) developed an intuitive model of viewing organisations on a three-layer-basis, within which artefacts are those elements that are readily observable at the surface: dress, furniture and technology. In their treatment of the technology literature, Orlikowski and Iocono (2001) surmise that a tool or artefact usefully reveals labour substitution, performance enhancing, information processing and social relations-enabling characteristics. Perhaps overlooked artefacts are documents, for example, menus and cookbooks, as they constitute 
'how to do it manuals' but often are written in the obscure language of the chef (FuentesLuque, 2017). Similarly, career resumés (or curricula vitae) as autobiography (Olney, 2017), reveal a career of 'doing', and while not necessarily an organisational artefact, they certainly are a portable occupational artefact. Thus, artefacts are both material and immaterial phenomena; artefacts may be language, acts and objects, and this category also contains values, beliefs and feelings (Yanow 2006).

In many workplace contexts, including kitchens, artefacts are associated with the implements that distinguish the craft or profession and can take on an aesthetic persona and meaning with which the occupation then becomes widely identified. Chugh and Hancock (2009:464) note that "the role of the non-human artefact has provided a major source of interest for those concerned with charting organizational landscapes and the aestheticization processes they engender". Riemer (1977:89) highlights the significance of these implements when he opines that:

The 'tools of one's trade' are one of the more important accoutrements of the skilled tradesman. The tools themselves, how they are used, and when they are used, become critical indicators of skill and expertise.

The agency of these objects then is to signal the skills and craft of the imagined user. Lundberg and Sandahl (1999:370) see artefacts as evolving from the commonplace to enshrine significance beyond their utilitarian value when they note:

how artifacts' peripheral properties become common resources that over time the communities of practices rely on. These resources, residing as they do 'beyond the object', seem to us important to understand in the process of understanding work. Brown and Duguid (1994) recognise this transition from the ordinary in the context of design, whereby artefacts may acquire features and attributes of an aesthetic nature beyond their practical value or utility. Groce (1989:391-2) states that "members of social groups use 
artefacts which have practical or symbolic importance, they develop specialized language or argot and they create and sustain ideologies".

In the specific context of this paper, artefacts are also recognised in terms of their nostalgic value, even sustaining ideologies, especially to those who have been displaced from the workplace through retirement. As Milligan (2003:381) notes "nostalgia often emerges after displacement as individuals attempt to regain a sense of identity continuity through recognizing and redefining a shared past”. Milligan's interest specifically focuses on place attachment. In terms of artefacts, it is argued here that these can act as a proxy for place in evoking memories of culture and community among those who have left that place (work) and thus instils a sense of identity within that community based on the shared experiences that are associated with particular artefacts (cf. Gabriel, 1993; Strangleman, 1999). These memories then imbue artefacts with temporal as well as spatial characteristics - such that they maintain, even acquire, agency over time - be that across careers, or as our study of chefs finds, beyond their kitchen careers - and that they transcend place.

Chefs, Cooks and Artefacts

Undoubtedly, the most visible occupational artefact of the chef is their uniform and there is a good deal of mythologising regarding its origins (cf. Andersen, 2004; Culinary Institute of America, 2001; Sockrider, 2005). The traditional uniform's components are the toque blanche (chef's hat), neckerchief, white double-breasted jacket, a long white waisted apron and black and white checked trousers (traditionally in a tight hound's tooth pattern). There are practical reasons explaining the uniform's features; the toque is intended to prevent hair finding its way into preparations, the neckerchief mops up sweat, the double-breast of the jacket protects the wearer from frontal heat and can be reversed to disguise the evidence of a chef's labour when ceremonial duties call and the tight trouser checks too obscure stains. 
Chef uniforms play a role in establishing the kitchen hierarchy, similar to that found in military organisations. Saunders (1981:122) explains, in a long passage that we only briefly extract from, and evidently from within a particular cultural and geographic milieu, how distinctions in terms of status (and distain) between chefs are symbolically expressed through the dress codes found in traditional kitchens.

The height of a chef's hat indicates his rank in the social order, while small, sensible article or cloth hats are associated with 'cowboys'. Aprons... worn above the knee are associated with the worst American cookery, or a lack of feeling for food. ... Collar and tie is worn only by the head chef....

Occupational artefacts of chefs extend beyond apparel, or the uniform. Items of equipment, for example knives, steel, tools, gadgets, the toolkit and/or knife scroll/box come to mind. These are frequently personally-owned rather than employer-provided - evoking the medieval notion of the master craftsman who is mobile with the tools of their trade. Moreover, a range of documentary artefacts, ephemera and memorabilia could be considered items that chefs cherish and so retain.

The occupational artefacts of professional chefs clearly represent duality in terms of Latour's (1992) distinction between technological and symbolic artefacts, duality in the sense that a single artefact (the knife, for example) may consecutively and/or simultaneously represent both the technological (what I do and how I do it) and the symbolic (who I am as both others and I see it). This duality is at the heart of our study in this paper.

\section{Research design and methods}

Methodologically, this research adopts a qualitative approach and interpretation is conducted from a social constructionist perspective (Burr, 2006), cognisant that chefs were active agents in shaping their occupational community and culture yet synchronously subject 
to its impositions. This allowed our inductive analysis and interpretations to emerge from the accounts of our respondent chefs. We were then able to consider the relationship between our data and extant theory and found that an approach, drawing on new materialism, allowed for an interpretation of these data that was both intuitively and theoretically sound as a lens through which to assess artefacts in the workplace and beyond. We will return to new materialism as a theoretical 'tool' later in this section.

Data for this study are derived from a concatenated series of 52 semi-structured and in-depth interviews with chefs and former chefs, conducted in Australia (see appendix 1). Australia, like many developed countries, continues the traditions and training of modern cookery, as institutionalised in late Victorian England (Escoffier, 1987). The sample, described in more detail below, displayed high international mobility, indicative that Australia is reflective of the shared occupational community and culture of chefs. The location of the study, and recruitment of participants, including snowballing, allowed for some triangulation of data. Some participants spoke of others in the study, which allowed a cross-examination and validation of findings, in that the researchers had access to data beyond self-report in the case of working conditions at a particular employer, or claims individuals made of themselves. This allowed for richer (re)interpretations of data. The wider focus of the parent study lay elsewhere, in investigating broader occupational selection, socialisation and professionalisation issues, occupational satisfaction and career intentions. Data on the artefacts of the chefs' occupational community and how they relate to the objects that symbolised their status within this community and beyond, emerged somewhat serendipitously, but was a consistent theme that sought explanation. Indeed, clothing and equipment have been probed as occupational characteristics in previous studies (e.g. Palmer et al., 2010). 
The principal researcher's emic status (cf. Botterill, 2000), as a member of the chef community, allowed for a rich rapport to develop such that interviews manifest as conversations. Thus, besides preserving anonymity, participant [pseudo] names are used in reporting the findings to highlight this relationship. This rapport was important since the study's underpinning construct was occupational culture and community. It was in this way that discussion of the artefacts of the occupation; their relevance, importance, symbolic and nostalgic significance, surfaced. Interviews typically lasted from 90 minutes upwards. Dependant on situation, given some interviews were conducted opportunistically, audio recordings were taken and transcribed $(n=35)$. Otherwise, extensive field notes were taken $(n=17)$. All the audio recorded interviews were imported and managed in NVivo ${ }^{\circledR}$ together with the extended field notes. Content analysis was initially used to identify and organise these data (Krippendorff, 2004) relevant to this enquiry. Finally, thematic analysis, guided by the occupational community and occupational artefact literatures (cf Bechky, 2003; Halverson, 2003: Lundberg \& Sandahl, 1999; Steiger, 1993), was used to capture latent themes. Given the new materialist focus was on the agency of objects themselves, themes were developed around grouping the specific occupational artefacts the chefs described, for example articles of the uniform, tools, ephemera and so on.

Many of the chefs interviewed had worked across the globe and related experiences in varied industrial contexts that included roles in royal palaces and on private luxury yachts for the exceedingly wealthy. Others worked in Michelin star and award-winning restaurants and in boutique gentlemen's clubs and some had competed at prestigious international Salon Culinaire competitions. Many had practiced with a range of international hotel and resort chains, on luxury cruise liners and with national institutional caterers. At the other end of the hospitality industry spectrum, the participants recounted working in local hotels (pubs), suburban cafes, franchised coffee shops, pizzerias, in sporting, community and striptease 
clubs and even desert truck stops. At time of interview, 34 of the participants were still practicing and two were employed as cookery trainers. Of the remainder, 12 had retired from professional cookery, although three of these retirees still worked in the hospitality or auxiliary industries, and one chef was on maternity leave.

The sample was predominantly Australian (63\%) but British, Irish, French, German, Hungarian, Belgian, South African, Singaporean, Ecuadorian and New Zealand born chefs were also represented in the group. At $63 \%$, males dominated the sample. The age of participants, at time of interview, ranged from 19 to 70 and the median age group was 35-50 years old. Collectively, the sample combined over 800 years of experience working as professional chefs and had practiced across Australasia, in the UK, Europe, the Americas, Asia and the Middle East. A short descriptor of participants is offered the first time they are introduced in the data-driven discussion that follows.

These data, therefore, were rich and deep and our initial interpretation, perhaps, simplistic and inconclusive in enabling the development of meaningful theoretical framing. Returning with a lens derived from new materialism enabled us to make somewhat clearer sense of these data. New materialism can be seen as a reaction against the dominant narrative of " 'culture', 'discourse', 'language', 'the semiotic' and so on, to the detriment of 'matter' " (Sullivan, 2012:300, see also Barad, 2003) in social constructionism discourse. It is not a reaction without challenge and the debate between social constructionism and new materialism remains very much alive (Sullivan, 2012). Fowler and Harris (2015) represent this debate as a choice between viewing the physical as representing bundles of complex, socially constructed relations, or as things-in-themselves, existing independently of how we relate to or use them. Fowler and Harris (2015) ultimately reach the conclusion that both perspectives co-exist and that material things need to be interpreted from both sides of this duality. Our study of chefs, artefacts backs up this position and leads us to adopt a Latourian 
position in recognition of both the intrinsic value of each artefact as a material object (technological) and its complex and contested symbolic status. Fowler and Harris highlight a paradox with Latour in the way that he talks about artefacts both as real entities that enter relations, while also acknowledging that these entities themselves are constituted from relations. This paradox or duality is important in our discussion here. New materialism as an analytical standpoint is not the preserve of any one discipline or science and is manifest in the work of archaeologists, anthropologists, biologists, physicists, engineers, performing artists and philosophers, to name but a few, and we see this contribution as introducing a new context to the discussion. The recognition of new materialist interpretation alongside a honing in on our chefs' artefacts through social construction provided a powerful tool within our analytical process and helped to frame the outcomes of this study in a significant way.

\section{Occupational Artefact Typologies}

An indication of various occupational artefacts that might be valued by chefs, and how they are retained as keepsakes and mementos, was provided earlier and the data revealed that many of these carried organisational, systemic, individual (Wood, 1966) and occupational meaning. A range of discourses emerged from the interviews, but the ensuing discussion is arranged by a typology of the artefacts that emerged, rather than by themes, since the breadth of these is as revelatory as their interpreted meanings.

\section{Uniform}

As expected, much was revealed about the uniform, which was even reported as an attraction to the occupation. Brooke, a middle-aged woman who had nearly 30 years of kitchen experience in multiple sectors, recalled, "I supposed [sic] you first want to be a chef, it is the uniform. There is a little bit of something to it... authority", according with a symbol 
of status (Bakó, 2010). The uniform was absolutely integral to occupational membership and this was inculcated during training. Dale, a junior commis ${ }^{1}$ who trained in Ecuador, related that she first learnt the trade "in a beautiful school [from] people in uniforms so clean and 'cool'" and Suzie, an experienced consummate professional chef who now worked in a community club, "missed the traditionalism of dressing in 'whites' ... that has been a pleasure". In a sense, therefore, to have the right to wear a chefs' jacket conveyed a rite of passage and socialisation discourse.

The communal value of the uniform was apparent in the distain chefs had for those that did not respect it, or those who were perceived to be unfitting of the privilege. Young apprentices who "you see with their chef pants and their shirts and they are filthy and they are walking around like... they come into 'Maccas' [McDonalds restaurants]. Just not very good for the image [of the occupation]", bemoaned Ebby, a 19-year old apprentice. Thomas, an award-winning chef of over 30 years' experience, sarcastically explained, “they slap a jacket on them and there you go - you are a chef! You [they] are not qualified but because there is such a lack in the industry for qualified chefs, you get a 'monkey' and put a jacket on them... a lot of 'never was's' around too who put jackets on and claim to be chefs". Thomas wore his jacket with pride even though the establishment he was now employed in didn't do justice to his professional expertise and skills - an employment choice he made as a consequence of personal circumstances. In this sense, the uniform was symbolic of what he could do rather than what he currently had to do. As such, the uniform was an artefact that reassured him of his identity and was a tool that communicated this to his work colleagues, managers and customers (Wood, 1966).

On the other hand, there was evidence that those in positions of authority in the kitchen demonstrated their power by mix and matching various articles of attire that

\footnotetext{
${ }^{1}$ A line cook
} 
constituted the traditional chef uniform (see Andersen, 2004). A kitchen, where now-retired Matt had previously worked, was headed up by a Michelin star chef. "I [had] total respect for the guy. We used to bag [tease] him because he used to work in a pair of jeans sometimes, and he goes 'the jeans do not make me cook any better"' Paradoxically, the Michelin star chef was demonstrating that his occupational status transcended the symbolism of the occupation's artefacts. Rowdy, a dubious character - vague about his past when queried and with a resumé which far outshone the respect of his peers - fancied himself as a ladies' man. He routinely wore black trousers to assert his status - typically executive chefs don't wear the classic hound's tooth checked pants, so Rowdy sought to differentiate himself both from the rest of his brigade ${ }^{2}$, but also to those outside it - "the girls [waiters] go wild on that authority, don't they?" he added. Enough of the chefs' uniform was kept in these two cases to assert 'occupational jurisdiction' (Bechky, 2003), an interesting observation given the various colourful and stylistic variations now worn by chefs (Sockrider, 2005), that vary from the traditional uniform. Otherwise, dependant on sector, chefs mostly conformed to the culturally-conditioned double-breasted jacket, checked trousers and apron, that Dale, Ebby and Suzie referred to in somewhat rarefied tones. In more upmarket establishments the neckerchief and toque blanche were frequently added.

Collecting behaviours also emerged. Charles, at time of interviewing, was the chief executive officer of an industry training association, which was principally engaged in the training and placement of apprentice chefs. On the back of the door in his office, hung his signature-embroided jacket, even though he had long since been retired from the kitchen. This relic of his time in the kitchen authenticated his occupational rite of passage, his individual status (Andersen, 2004) and legitimated his authority in the organisation despite the fact he no longer cooked. Contrarily, when Stan left his last ever chef job, after 18 years

\footnotetext{
${ }^{2}$ A team of chefs that work in the same kitchen, or at least establishment
} 
in the occupation, he recalled receiving, as a farewell gift from the kitchen brigade he had led for several years, a picture framed old tattered jacket, signed in permanent marker pen and embellished with other occupational and personal ephemera, with a note 'break in case of emergency'. While, ironically, the gift did break in a relocation some years later, here a dialogical mobilisation of the artefact is evident. On the one hand, the brigade conferred on Stan a temporarily unbound occupational status, in that he would always be a chef, as a pilot is always a pilot (Fraher \& Gabriel, 2014). On the other hand, Stan's acceptance and cherishing of the composition acted as a memento of a career - and an enduring identity. Perhaps Ebby too, already talking about life after cooking, spoke about a business partnership with her father, "a warehouse sort of thing, like tools and uniforms". She seemingly already envisages a place for these occupational artefacts in her life beyond professional cookery, even if they are not hers. As with previous studies (Palmer et al., 2010), the chef's clothing conveyed strong community membership so it is unsurprising chefs valued their occupational apparel but also redundantly retained them into retirement.

There was limited discussion about other items of apparel. Some revolved around the toque blanche. There were suggestions that it was an artefact symbolic of status (Bakó, 2010) especially in more upmarket establishments where "they will require you [to] have to wear a certain hat or whatever", related Seb, a young pub chef, who was keen to demonstrate his pedigree throughout his interview. Although it was no longer required in his workplace, Seb was leveraging the significance of the toque blanche by association, to demonstrate that he understood what it was to be a 'real chef'. Retired Stan still keeps his cloth toque blanche, neatly wedged between a couple of branded aprons of sentimental value, with a hardly worn former "special occasion jacket" in a cupboard - trophied items singularly nostalgic. Cath, long since retired from cookery, still also keeps her "special selection of lucky aprons". Seemingly, the jacket is the artefact overwhelmingly highest on the consciousness of working 
and retired chefs, and unlike the literature tabled earlier in this article regarding its origins, its practical utility is rarely considered.

Equipment

Tools of the trade, or equipment, were frequently referred to by the chefs. Certainly, equipment was a valuable occupational artefact as Thomas illustrates: "you got to respect, to respect your equipment". The most common context was as a hindrance to the participants' standards due to the equipment's inadequacy or absence. Chefs were defined by "the equipment you have to work with", declared Gary, a former award-winning chef who now plied his trade heading up a small community club kitchen. Without equipment chefs felt compromised so much so that if "there are some things I need, I go down there [another kitchen across the road] and like steal some of their equipment and whatever - sort of borrow", confessed Sam, a single mother, with a limited culinary repertoire (as disclosed by her peers and employment context). Professionals who did not have the right tools, Gary added, became "fitters and turners", a disparaging colloquialism for unprofessional cooks, "rather than chefs" so tools became an intra-occupational boundary marker (Carlile, 2002). Some chefs kept personal equipment in their kits - cutters, molds, dishes and so on. Cath still kept "a dirty old battered low-sided square cake tin that I used to use as my steak resting container" as a nostalgic trophy of her days as the chef/manager of her own restaurant.

Of all kitchen equipment that chefs take pride in, undoubtedly their knives are most prized. Knives, like other tools of the trade are mobilised in the practice of demonstrating skill (cf. Steiger, 1993). Knives are personal items and even their loaning to other chefs, let alone foodservice staff, was rarely tolerated. Chefs spoke disparagingly of those that disrespected their knives, "he was using his knife incorrectly and had no respect for the 
knife", Fe, a mature-aged female club chef, recalled. Likewise, situations in which the skill was not upheld were despised: "so, I know a lot of kitchens in that they have gone like knifefree [and] everything comes in prepared like your carrots cut in everything like that, like hell... that is sad", related Sam. Jacob, reflects on the currency of his knowledge and skills: "it comes down to when I am going use it? Am I going to use it next week or in five years' time? ...a lot of stuff is lost because you are not doing it”. Deskilled kitchens, ubiquitous as they are (Robinson \& Barron, 2007), provide a counterpoint for the cherishing of the tools that enable the display of skills (Riemer, 1977).

Many chefs spoke of how they kept their knives in pride of place, even into their retirement. Cath's 'tool box and knife roll [are] intact, 'ready for action' in front of the burners!", in her home, mark them as working relics of her career but constant reminders too, of the honourable nature of honest tradesman's work (Ashforth and Kreiner, 1999; Sennett, 2008) and the ideologies captured in their ability to demonstrate (now redundant) skills (Steiger, 1993). Equally, Stan stores his knives and gadgets at home in his old toolbox and they are most deliberately separated from the domestic culinary items of his home. Symbolically, this could be interpreted as keeping apart the artefacts of an occupation from those deployed daily in the home - providing clear boundary-marking (Carlile, 2002) between objects of everyday utility from those of occupational significance.

On the other hand, Chikka, a well-travelled chef but since retired from cooking, alluded to the marginal practices of the occupation when detailing how he acquired a couple of prized knives that he now uses at home.

[There] was a German blade (knife) that was sold to me by another apprentice at college for half price (not sure where he got it)... Another knife I have is a serrated blade that I took from a place in London where I was 'temping'. [I'm] not very proud 
of that fact and I seem to recall there was some issue with the management of the place that helped me justify the act at the time.

This second acquisition demonstrates an equalising motivation (Harris and Ogbanna, 2002), and suggests the value of the artefact, economically and symbolically, compensated for any perceived exploitation. Less illicitly, Eric, an experienced fine-dining and international hotel executive chef, trophied a “carving knife with boar's foot handle. This item was hand crafted, but the restaurant needed to replace it as the blade was damaged, so [he] "acquired it as a souvenir before leaving” the Belgian two star Michelin restaurant where he plied his trade post-apprenticeship in the 1980s. These occupational artefacts had performative functions (Goffman, 1959), which added to their value.

Itinerant chefs depended upon more than just their knives to maintain their standards. Dwayne, a middle-aged former hotel chef, related the story of an acquaintance for whom an array of occupational artefacts conveys a professional membership:

[H] e carries knifes, cutting boards, pots and pans and everything in his car because he is sick of turning up in kitchens where the cutting boards are green and mouldy and feral infested poly-boards and all that. He even carries his own chemicals in his car so he can have a bit of a clean before he starts. Again, old school, he takes a lot of pride.

Here, artefacts are mobilised, manifestly as allowing chefs to maintain their standards, but there is a latent suggestion that the integrity of the professional chef will endure in the face of disappearing industry practices. Knives, perhaps, above all, symbolise Milligan's (2003) displacement nostalgia best for those no longer working as chefs. They clearly represent much of the pride and sense of community belonging to and associated with a former working life. 
Documents and ephemera

Besides equipment, chefs clearly cherish a range of occupational artefacts specific to their craft. Of all the chef's occupational artefacts the cookbook was most often cited as an item of value. This may partially be because of their economic value, since chefs mentioned they had copies of the expensive Repertoire de la Cuisine and Larouse Gastronomique. This latter volume would have been a significant outlay for apprentice chefs, which is when they were usually purchased. While 30s-something Kris, something of a journeyman now trading in real estate, confessed, "I do have some old cook books, which I haven't looked at for a long time". Others, like Fe, admitted addictive tendencies:

I have got old cookbooks, I have got cookbooks from 1876... when you are going through bookshops and something like that, there is a nice book and people give them to you if they know you are interested. I am not allowed to buy any more cookbooks but I still do. My husband said 'no, that is enough cookbooks'. But like I said, I like to get Korean cookbooks so we end up buying one from Sujan.

However, Al, easing into retirement as a short-order cook at a suburban café, went on to add that "I was a third-generation chef so I have cookbooks handed down to me from my grandmother in New Zealand from the 1800s that I still cook out off - yeah, so great sentimental value". These cookbooks offered Al the status of occupational lineage and pedigree (Bakó, 2010), despite the fact he practised in a suburban cafe. Evidently, cookbooks, in the ownership of a chef, as opposed to the housewife or culinary enthusiast, carry a complexity of temporal, spatial, familial and occupational agency and capital.

Similarly, a variety of magazines, from Woman's Day to table top glossies like Gourmet Traveller were subscribed and collected by many of the chefs, supplementing their cookbook collections. "Yes, I get one magazine these days Cuisine, the New Zealand cooking one", illustrates Tiny, a just married chef working at a local fish and chip shop. Gary 
suggested that a sign of lacking commitment to the occupation by young apprentices was that they didn't look at these referential sources. Perhaps this is why Stan, although admitting that he now scours the internet when in need of a recipe, "still keep[s] about ten years' worth of Gourmet Travellers in a cupboard", in his home office, and despite their lack of use "I'll never throw them away". Recipes also appeared in various retained custodian hand-written exercise books. Kris, something of a occupational journeyman and now trading in real estate, began collecting from "day one of his apprenticeship" and still maintains "a collection of a lot of recipes". These collectibles, accrued during occupational journeying, are suggestive of their totemic value long after their occupational utility has passed.

While a resumé itself is hardly a collectible item, a closer reading of their meanings indicated that they were seen as an artefact tracking occupational experiences. Young entrants explained the value of working at a prestigious restaurant, despite indifferent experiences as "good. I think that was probably a resumé thing" (Kris). That is "why chefs go to Europe to work in the Michelin stars, [so] it is on their resumé”, explains Matt. The resumé then, is a tangible occupational artefact recollecting their career achievements. Thomas adds:

I think that if you have got good restaurants in your resumé ...there are probably perfectly good chefs, exceptional chefs who have worked all their life in RSL [worker's] or clubs. But you are... you are seen in a higher esteem if you worked in good restaurants.

Certificates, an adjunct to the resumé, carried significant occupational community capital. "If I am going to keep cooking for my whole life, I might as well get a [trade qualification] certificate for all of this", middle-aged club chef Catherine explained, which supported the distinction between cooks and chefs that most chefs are at pains to point out. Hence a trade certificate is a significant occupational artefact for both those with and without one. Suzie explained that she originally "got my qualifications in Darwin, Northern Territory...” but 
some time ago undertook a post-trade qualification "to be an executive chef" and then a “further certificate". Certificates need not be seen, just their acquisition denoted status (Bechky, 2003).

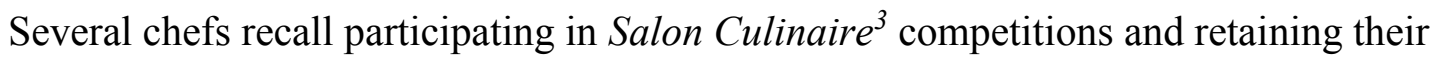
certificates and medals. Gary "represented Australia in London as a Culinary Olympian in 1981" and Jim, who had abandoned cookery, after his idealistic celebrity chef dreams were dashed by a single failed audition, to be a dog-catcher with the local council "did a few competitions... I got second in 2005!" Melanie, a former club chef, "got a bronze medal", which she keeps in a separate location at home, perhaps even more sentimentally valuable since she now works as a jewellery retailer. Eric still keeps a "Gold Plate Award won by Zigmund's", the fine dining restaurant of a hotel where he was the executive chef in the early 1990s.

[I] took this [award] as all but one staff member involved with winning the award had left. The food and beverage manager had his eyes on it and as he was a real tosser [idiot], I acquired it in clandestine fashion.

Similarly, the theme of deviant behaviour, to recoup what the chef perceived to be rightfully theirs, occupationally as much as individually, emerges from data (Ackroyd and Thompson, 1999). While Adolf, a baker then chef, initially dismissed some organisational certificates he had received throughout his career "from the management" as "just piece of article in a frame" their value to him was betrayed both by the fact he still kept them (despite being 70 and fully retired) and that they represented "some recognition of... yes, recognition". Similarly, Eric has kept gifts like show plates and hand-crafted cheeseboards that fit into a wine barrel top, which were presented to him by a hotel general manager when he was promoted and "by the chief executive officer of [an] International Hotel Group for promotion

\footnotetext{
${ }^{3}$ Salon Culinaire are prestigious cookery competitions for chefs
} 
and transfer back to the [Australian] property to take over as executive chef'. These occupational artefacts were symbolic of performing on a more grandiose stage, to appropriate Goffman's (1959) dramaturgical metaphor (see also Morgan, 1983), and hence signified the status of artist (Peterson and Birg, 1988) as distinct from everyday craftsman (Ashforth and Kreiner, 1999).

A range of other ephemera surfaced as collectibles of personal and occupational importance from plates, glass and silver wear, branded bottle openers, even a rarely seen Raclette cheese toaster. The chefs reported that these were items that were sometimes surplus to operational needs, unused supplier samples or left-overs from promotional functions and old menus. Other ephemera was of high personal value, like Cath's apprenticeship “first-ever payslip" to her business cards. Equally, Cath still kept her "very first bottle of imported, ridiculously expensive, EVOO [extra virgin olive oil]. I use that as my bedside water bottle". Rob keeps a "huge collection of photos" carefully arranged chronologically, not just of dishes he has prepared but also some of kitchen antics that only the occupational community would approve of, and possibly understand (Lynch, 2009). Stan, too, keeps "colour photographs of degustation [multi-course] dinners [he] prepared" and of guests that he developed special relationships with while working as the executive chef of a private club. Some photographic records though, are vilified. Gary, the former culinary Olympian, explains he was asked to partake in a promotional campaign.

Management will come to you and say, 'Someone will take some photos of you or some food in our menu'. You look at the [menu]board and you look back at your career in your own mind and you think, 'they are going to put my name on the front page of the local rag with a chicken schnitzel in my hands, like wow - bring down the clouds!' 
Gary, now a chef at a suburban sports club, in this self-deprecation is bemoaning the artefacts that now represent how his career had plummeted from its perceived former glories.

\section{Artefacts, agency, identity and nostalgia - using a new materialist 'blade'}

Our vista now turns to scrutinise the intrinsic value and voice of objects. In these data, and adopting a new materialist lens, we have detected the agency of artefacts in four (intersecting) forms. The first, according with the fundamentals of new materiality in a Latourian sense (1987), are artefacts as technology. These objects, or tools, had (neocapitalist) productive utility, although on occasions they also spoke incisively to the substitution of labour and therefore challenges to occupational identify. A second set of artefacts were predominantly symbolic. At once they reified the artistic/craftsman qualities of professional chefs and also the deviant practices defining an occupation 'on edge' creatively, physically and emotionally (cf Burrow et al., 2015). Third, were redundant artefacts. Rarely utilised in practice, or ceremonial only, these artefacts acted as, or were mediators to, an occupational community that valued 'things as they were' or 'ought to be'. And finally, were the artefacts that, whether previously useful, symbolic or redundant, in their occupational afterlife reclaimed agency through their utility as working, relational and/or referential material objects (Kuhn, Ashcraft \& Cooren, 2017). In so doing these artefacts assumed agency independent of their congenital occupational and organisational contexts. We contemplate these forms, mindful of our nostalgia narrative, in turn.

\section{Technological artefacts}

Tools of the trade denote expertise and skill (Riemer, 1977; Steiger, 1993). Equipment, at the most fundamental level, speaks to 'what happens here' even if nothing is actually happening. More specifically, equipment performs (or doesn't) an explicit function. 
As one of Latour's (2005) apposite contributions to organisational studies, things do things that influence or even dictate what we do and how - or the intrinsic connections between technology and human action. The visibility, or otherwise, in the case of deskilled kitchens, signalled what sort of kitchen this was - one where on the one hand a range of tools, like various gadgets, cutters, and molds produced an array of craftful and artistic creations (Fine, 1996) and on the other what chefs disparagingly describe as 'cowboy' kitchens, a la Sam's knifeless kitchens, replete with labour substitution (Orlikowski and Iacono, 2001). More than this, artefacts evoke nostalgia here, a nostalgia for what did or should happen, even if it doesn't. Thus, the agency of these material artefacts reinforces a collective occupational identity of the reified performative functions of cookery, even if absent or lost.

Tools then, assumed the role of intra-occupational boundary markers - between artists and craftsperson and Gary's derided "fitters and turners" (Carlile, 2002). The former, artists and craftperson, wore their toque blanche high, their aprons long, their jackets clean and their quality 'German blades' at hand to denote their superior occupational pride. This should not be confused with equipment speaking to the honourable tradesperson's 'pathos' (Robinson, et al., 2016) - perhaps a defensive posture reflecting the occupation's harsh realities, from Orwellian working conditions through to violence and bullying (Burrow et al., 2015). Cath's dirty old battered low-sided square cake tin represented this pathos - honest industry, or noble dirty work (Ashforth and Kreiner, 1999), as did Dwayne’s itinerant colleague's mobile cleaning chemicals. A further distinction is apparent between the various technologies the chefs described. Some equipment was for doing, in a functional, even trade or craft sense, like Fe's knives, whether respected or not. Other objects were for creating. Eric's boar's foot handled carving knife (trophy), was a carriage to transport the chef's skill and guile into the gaze of the dining guest, or as Griswold et al. (2013) would dramatically suggest, the knife was a medium for a choreographed encounter. 


\section{Symbolic artefacts}

Despite the somewhat tenuous reasonings explaining the functionality of various items of attire in the chefs' wardrobe (cf Andersen, 2004), the uniform, and other artefacts, are laden with deep symbolic meanings in and out of professional kitchens. The uniform, and its adjuncts like the toque and aprons, communicated legitimacy - Thomas' indignity at monkeys masquerading in jackets being a vivid example. Taking licence with the uniform, for example wearing black trousers instead of checks, for Rowdy, was a marker of authority and an identifier of status within a kitchen hierarchy, and thus illustrative of the uniform's independent agency as an intra-occupational boundary marker (Rafaeli and Vilnai-Yavetz, 2003). The uniform made chef monarch of the domain, the domain being the kitchen and monarch being an occupational jurisdiction (Bechky, 2003). This symbolism extended beyond the purview of the kitchen and into the public imagination. Here the highly mediatised nature of professional chefs and cookery takes root in that artefacts are juxtaposed in various contexts and combinations (Gunders, 2008), even outside kitchens, to symbolise 'the chef' and their occupation.

For the chefs however, in new domestic domains, the agency of uniforms morphed into nostalgic symbolism; Stan's gifted framed jacket, Charles' signature-embroided jacket and Cath's lucky aprons were not used at home or office yet retained their significance. While Nippert-Eng (1996) considers the importance of the agency, and symbolism, of objects as they frequently interchange between work and home domains, our evidence points to a more permanent agency thus evoking "the mediating role objects and environments play in meaning-making" (Griswold et al., 2013:360). Certificates of competence, such as trade articles and career resumés, marking membership of an occupational community, had little organisational utility, although they mediated mobility between employers, but were rarely 
discarded in the custodian's occupational retirement. Similarly, photos, once functional adjuncts to recipes in the guiding of standardising preparation and presentation (Robinson \& Barron, 2008), or to record antics or relationships remain referentially symbolic. These nostalgic artefacts all richly reference an erstwhile occupational reality (Milligan, 2003), yet an identity cauterised by shared lived experiences - with self-evident temporal dimensions.

\section{Redundant artefacts}

Perspectives drawn from the cultural/museology literature are useful in the framing of static objects that once enjoyed utility, but now reside in collections (cf. Pearce, 1994). This standpoint however, is biased towards the functional utility of artefacts, and thus permits us to reconsider 'utility' as it might intersect with memory and identity work and nostalgia. Examples here might include menus, awards, trophies, even pay-slips and business cards. Nostalgia, Stewart (2016:8) asserts, “operates on multiple levels within the culinary world”. Documents, like menus and recipes, and professional cookery magazines and books, are often written in language particular to chefs. Le Répertoire de la Cuisine, in Al's collection, a culinary guidebook for chefs, which contains only brief descriptions, assumes much background knowledge. However, while Stewart (2016) considered meals and ingredients and methods, missing in the author's consideration are the actual tools of production, or reference points.

In the context of chefs, it also permits a consideration of how they mobilise nostalgia of various occupational rhetorics; of artist/craftperson, worker and businessman (Fine, 1996). Artefacts provided their owners with tangible evidence of their inclusion to a traditional (artistic) occupation, although often they had limited utility in professional contexts. The toque was redundant in the sectors that many of the chefs practiced. In many deskilled (working) kitchens, the array of culinary gadgets a craftsman kept in their toolbox were rarely 
used - but their ownership was symbolic of a repertoire. A range of collectibles, while also symbolic of membership and legitimising authority, signified distinction acquired elsewhere. Old cookbooks, for example, established a pedigree - an affirmation for Fe of conversance in many cuisines and for Al that he was a third-generation chef. Cath's business card, of course spoke to a managerial rhetoric (Robinson et al., 2014).

Otherwise a range of artefacts, for example Eric's collection of knifes, awards and speciality crockery, glassware and equipment, can be understood in terms of Goffman's (1959) theatrical props, but represent those collected from an elevated stage. Magazines and trade publications, once sources of inspiration (Leschziner, 2007) become redundant in a fastpaced occupation governed by fads and fashion, especially at the upper echelons of finedining (Lane, 2014). Finally, cookbooks, as Leschziner (2007:87) observes "are cultural capital, but they are not acceptable work resources", as evident with our chefs who rarely used them at home.

\section{Utility in the occupational afterlife}

When considered independent of their occupational settings, many of the artefacts presented in this study are everyday objects (Lundberg and Sandahl, 1999) with as much utility in domestic kitchens as professional ones inter alia articles of the uniform like the apron, some tools and cookbooks. Yet they are mobilised as discursive resources by their custodians to give voice to a range of occupational identities, beliefs and values (Yanow 2006) and, indeed, in evoking nostalgic emotions. Nippert-Eng's (1996) use of concepts of boundary work represents this nostalgic dimension but not necessarily in negotiating the 'as it is', but rather engaging with their nexus 'as it was' - via the lens of occupational memory and vestiges. Stan's separation of his toolbox of professional knives and gadgets from the domestic culinary items of his home marked out occasions when he did use the former; to 
prepare special dishes or to entertain guests. When the toolbox came out with its contents, both symbolised an event beyond the mundane. Some items acquire new functions in the occupational afterlife, as exemplified by Cath's 'ridiculously expensive' imported EVOO bottle which now functions as a bedside water bottle.

\section{Conclusions}

The key contribution of this study is that it has revealed a number of temporal and spatial dimensions to the manner in which material occupational artefacts are imbued with meaning, reflecting Latour's duality, or paradox. The first is in the present and represents a reaffirmation of (occasionally imaginary) occupational community practices and values. The second, is a real, or imagined, frequently nostalgic and symbolic view of an archetypical occupational representation, which the custodian of an artefact either once practiced, aspires to or simply believes exists somewhere; the third, is the appropriation of occupational artefacts to cling onto an occupational past; and finally, there is the continued utility of the artefact, away from

the original context of its use (the professional kitchen) but fulfilling a common purpose. Using the lens of new materialism has helped us to identify and explicate these forms. To a greater or lesser extent, these dimensions invoke nostalgia, often facilitated by the retention of occupational artefacts that are professionally redundant in their present setting.

Beyond affirming the salience of a range of artefacts to an occupational community, this study highlights evidence of a range of practices. Artefacts were mobilised in the cultivation and management of positive occupational identities, particularly in how these reflect on individuals (Meisenbach, 2008). Retaining these artefacts provided their owners with tangible evidence of their inclusion to a traditional occupation, although often these objects had limited utility in professional contexts. The toque was infrequently worn in most 
sectors. A variety of culinary gadgets were hardly ever used - in the professional or domestic kitchen - but their ownership was symbolic of an aspirational skillset. A range of collectibles, while also symbolic of membership and legitimising authority, signified distinction acquired elsewhere - or even by someone else. Old cookbooks, for example, established a pedigree, even if never cooked from. Resumés also function in this manner, whereby these artefacts served as boundary markers between professionals and tradesman, between skilled artisans who had worked in Michelin star restaurants as opposed to 'cowboy kitchens' (Saunders, 1981). Otherwise a range of then and now performative artefacts (Goffman, 1959) included awards and speciality crockery, glassware and equipment. The lacking utility of many of these collectibles marks them out as objects eliciting occupational nostalgia, remnants of halcyon days.

Occupational artefacts hoarded in retirement however, function as pure objects of nostalgia providing a sense of continued membership of the occupational community to which they once belonged - an important statement with respect to the retained sense of identity of a number of participants in this study, especially those who migrated into allied occupations (Fejes and Köpsén, 2014). There is a clear sense of Milligan’s (2003) displacement nostalgia here with artefacts acting in some way as a proxy for the wider workplace to which chefs no longer have access. The sense of retaining membership of a community once formal ties have been cut, of course, is not unique to chefs. Fraher and Gabriel (2014) highlight the sense of loss of airline pilots experience when they cease to fly due to retrenchment, while retaining a sense of belonging to their former professional group. While there was no evidence in Fraher and Gabriel's study that pilots collected occupational artefacts in their need to retain identity, their sense of lost identity was palpable. Though not 'dreaming to cook again', indeed many had left cookery because they were burnt out and 
disillusioned (Rowley \& Purcell, 2001), the chefs turned to the material agency of their occupational tools, which assumed the status of totems and trophies.

The renowned mobility of chefs during their working careers lent itself well to the acquisition of occupational artefacts and these find expression in resumés and a range of ephemera from menus to photographic records of degustation dinners, to awards, medals and culinary competition certificates, which once allowed chefs to seek the acclaim of their peers. These artefacts, from across the other side of the world, and from another time, clearly have rich symbolism. There is a literature in the marginal behaviours of the hospitality industry and chefs (Robinson, 2008) and even a celebration of this theme in contemporary media (Hollows, 2003), even by chef writers (Bourdain, 2000). This discourse has surfaced as chefs collecting memorabilia symbolic of their deviant behaviours. The motivation for acquiring the objects seemed to be an issue of equalising, or claiming what was rightly theirs (Harris and Ogbonna, 2002), and denying illegitimate claimants thus marked out an occupational boundary (Carlile, 2002). As Eric and Chikka's recollections exemplify, these collected artefacts reminded them that they had got their own back, long past any practical contemporary utility. Moreover, these artefacts travelled a long way, as have many chefs in this study, to their current homes, in Australia. This leads to the generation of another critical point, that the occupational artefacts disclosed in this study are inherently characterised by their portability. The ramifications of this, coupled with the renowned mobility of chefs (Rowley \& Purcell, 2001), is that unlike previous studies which have largely focused on the import of occupational artefacts within the parameters of organisations, their meanings can be considered as they transcend the organisational unit, and even the industrial and geographic context. As Milligan (2003) has argued artefacts and the memories associated with them evoke attachment to place - in this case not various global destinations but the professional kitchen. 
Thus, this investigation has extended our understanding by bringing to focus the value placed on occupational artefacts both in the workplace and within the personal space of home (cf Nippert-Eng, 1996), as they are acquired during working careers and, nostalgically, into retirement. Their original utility was both material and symbolic and this duality persists into retirement. There is compelling evidence to suggest that an array of chefs' tools of the trade is highly symbolic as occupational artefacts while also naturally offering professional utility. However, a range of behaviours suggest that many of these occupational artefacts assume the status of totems with symbolic and nostalgic value even though they may become redundant in a practical sense through career change or retirement. The material declines in importance into retirement while symbolic status grows (cf Groce, 1989). This latter point is intimately associated with the individual chef and their career and it would be of future research interest to determine whether the symbolic importance vested in these artefacts extends beyond the lifespan of that individual, and indeed tease out gender differences and so gendered politics (cf Hinton, 2014). Therefore, while this study marks new directions in occupational studies, there is much opportunity to set further research agendas to better conceptualise the role of occupational artefacts, including mediums and produce chefs work with (Leschziner, 2007), and indeed memories of work and career.

One intriguing direction is to consider the practices and processes holistically rather than taxonomically. For example, embedded in many of the artefacts are journeys in socialisation, professionalisation and entire careers - indeed, lives. Menus, cookbooks, ephemera, even uniforms likely could be mined to reveal discursive narratives - of the 'gaining of wisdom' type but also of the accumulation of occupational agency and capital, and of identify formation, loss and transition. While this study has investigated a singular profession, one which intrusive mediatisation (Gunders, 2008), and complex rhetorics (Fine, 1996), have brought it to the forefront of community consciousness, no doubt the constructs, 
conceptualisations and theorisations can be applied, and tried, across myriad occupations and professions. 


\section{References}

Ackroyd S and Thompson P (1999) Organizational Misbehaviour. London: Thousand Oaks. Andersen OJ (2004) The evolution of the chef uniform. Unpublished Masters Dissertation: University of Adelaide, Adelaide.

Ashforth BE and Kreiner GE (1999) 'How can you do it?': Dirty work and the challenge of constructing a positive identity. The Academy of Management Review 24(3):413-434.

Bakó R (2010) Organizational discourses as status symbols, Acta Universitatis Sapientiae, Philologica 2(1):151-160

Barad K (2003) Posthumanist performativity: Toward an understanding of how matter comes to matter. Signs: Journal of Women in Culture and Society 28(3):801-831

Bechky BA (2003) Object lessons: Workplace artifacts as representations of occupational jurisdiction. American Journal of Sociology 109(3):720-752.

Botterill D (2000) Social scientific ways of knowing. In Lashley C, Morrison A (eds) In Search of Hospitality: Theoretical Perspectives and Debates. Oxford: Butterworth Heinemann, 177-197.

Bourdain A (2000) Kitchen Confidential: Adventures in the Culinary Underbelly. London: Bloomsbury.

Brown J and Duguid P (1994) Borderline Issues: Social and Material Aspects of Design, Human-Computer Interaction 9:3-36.

Burr V (2006) An introduction to social constructionism. London: Routledge.

Burrow R Smith J and Yakinthou C (2015). 'Yes Chef': life at the vanguard of culinary excellence. Work Employment and Society, 29(4):673-681.

Cameron D Gore J Desombre T and Riley M (1999) An examination of the reciprocal affects of occupation culture and organisation culture: The case of chefs in hotels. International Journal of Hospitality Management 18(3):225-234 
Carlile PR (2002) A pragmatic view of knowledge and boundaries: boundary objects in new product development. Organization Science 13:442-55.

Chugh S and Hancock P (2009) Networks of aestheticization: The architecture, artefacts and embodiment of hairdressing salons. Work Employment and Society 23(3):460-476.

Cooper J Giousmpasoglou C and Marinakou E (2017) Occupational identity and culture: The case of Michelin-starred chefs, International Journal of Contemporary Hospitality Management, 29(5):1362-1379

Culinary Institute of America (2001) The chef's uniform. Gastronomica: The Journal of Food and Culture 1(1):88-91.

Cullen F (2010) Phenomenological views and analysis of culinary arts student attitudes to national and international internships. Journal of Culinary Science and Technology $8(2): 87-105$.

Elkjaer B and Huysman M (2008) Social worlds theory and the power of tension: In Barry D, Hansen H (eds) The SAGE Handbook of New Approaches in Management and Organization. London: Sage, 170-177.

Eriksson-Zetterquist U Lindberg K and Styhre A (2009) When the good times are over: Professionals encountering new technology. Human Relations 62(8):1145-1170.

Escoffier MR (1987) The chef in society: Origins and development. Hospitality Review 5(1):50-57.

Fejes A and Köpsén S (2014) Vocational teachers' identity formation through boundary crossing. Journal of Education and Work, 27(3):265-283

Fine GA (1996) Justifying work: Occupational rhetorics as resources in restaurant kitchens. Administrative Science Quarterly 41(1):90-116.

Fowler C and Harris O (2015) Enduring relations: Exploring a paradox of new materialism. Journal of Material Culture 20(2):127-148 
Fraher A and Gabriel Y (2014) Dreaming of flying when grounded: Occupational identity and occupational fantasies of furloughed airline pilots. Journal of Management Studies 51(6):926-951.

Fuentes-Luque A (2017) An approach to analysing the quality of menu translations in southern Spain restaurants. Journal of Multilingual and Multicultural Development 38(2):177-188.

Gabriel Y (1993) Organizational Nostalgia: Reflections on 'The Golden Age' in (ed) Fineman S Emotion in Organizations, Newbury Park, CA: Sage, 118-141

Garrety K (1997) Social worlds, actor-networks and controversy: The case of cholesterol, dietary fat and heart disease. Social Studies of Science 27:727-773.

Geertz C (1973) The Interpretation of Cultures: Selected Essays. New York: Basic.

Greenfield G and Rohde F (2009) Technology acceptance: Not all organisations or workers may be the same. International Journal of Accounting Information Systems 10(4):263-272.

Griswold W Mangione G and McDonnell TE (2013) Objects, words, and bodies in space: Bringing materiality into cultural analysis. Qualitative Sociology 36(4):343-364.

Groce S (1989) Occupational rhetoric and ideology: A comparison of copy and original music performers. Qualitative Sociology 12(4):391-410

Goffman E (1959) The Presentation of Self in Everyday Life. New York: Anchor Books.

Guerrier, Y., \& Adib, A. (2003). Work at leisure and leisure at work: A study of the emotional labour of tour reps. Human Relations, 56(11), 1399-1417.

Gunders J (2008) Professionalism, place, and authenticity in 'The Cook and the Chef'. Emotion, Space and Society 1(2):119-126.

Halverson R (2003) Systems of practice: How leaders use artefacts to create professional community in schools. Educational Policy Analysis Archives 11(37):1-34. 
Harrington RJ (2005) Chef as CEO: An analogy and teaching tool. Journal of Culinary Science and Technology 4(1):39-52.

Harris LC and Ogbonna E (2002) Exploring service sabotage: The antecedents, types and consequences of frontline, deviant, antiservice behaviors. Journal of Service Research 4(3):163-183.

Hinton P (2014) 'Situated knowledges' and new materialism(s): Rethinking a politics of location. Women: A Cultural Review 25(1):99-113.

Hollows J (2003) Oliver's twist - leisure, labour and domestic masculinity in The Naked Chef. International Journal of Cultural Studies 6(2):229-248.

Jarzabkowski P Spee AP and Smets M (2013) Material artifacts: Practices for doing strategy with 'stuff'. European Management Journal 31(1):41-54.

Kaghan W and Lounsbury M (2006) Artefacts, articulation work, and institutional residue:

In Rafaeli A, Pratt M (eds) Artefacts and Organizations, Beyond Mere Symbolism, Mahwah, NJ: Lawrence Erlbaum Associates, 259-275

Krippendorff K (2004) Content Analysis: An Introduction to its Methodology. Thousand Oaks, CA: Sage.

Lane C (2014) The Cultivation of Taste: Chefs and the Organization of Fine Dining. New York: Oxford University Press.

Latour B (1987) Science in Action. How to follow scientists and engineers through society. Milton Keynes: Open University Press.

Latour B (1992) Where are the missing masses? The sociology of a few mundane artifacts. in Shaping Technology/Building Society: Studies in Sociotechnical Change. Bijker WE and Law J Cambridge: MIT Press, 225-258.

Latour B (2005) Reassembling the social: An introduction to actor-network-theory. Oxford: Oxford University Press. 
Leschziner V (2007) Kitchen stories: Patterns of recognition in contemporary high cuisine. Sociological Forum 22(1): 77-101.

Lloyd C Warhurst C and Dutton E (2013) The weakest link? Product market strategies, skill and pay in the hotel industry. Work, Employment and Society 27(2):254-271.

Lynch OH (2009) Kitchen antics: The importance of humor and maintaining professionalism at work. Journal of Applied Communication Research 37(4):444-464.

Lundberg N and Sandahl T (1999) What do Artifacts Mean to us in Work? Proceedings of the 22th IRIS Conference, Jyväskylä, Finland, 363-372.

Meisenbach RJ (2008) Working with tensions materiality, discourse, and (dis)empowerment. Occupational Identity Management Communication Quarterly 22(2):258-287.

Middleton G (2000) A preliminary study of chefs' attitudes and knowledge of healthy eating in Edinburgh's restaurants. International Journal of Hospitality Management 19(4):399-412.

Milligan M (2003) Displacement and Identity discontinuity: The Role of Nostalgia in Establishing New Identity Categories, Symbolic Interaction 26(3):381-403.

Morgan G (1983) More on metaphor: Why we cannot control tropes in administrative science? Administrative Science Quarterly 28:601-607.

Nippert-Eng C (1996,). Calendars and keys: The classification of "home" and "work". Sociological Forum 11(3):563-582.

Olney J (2017) Metaphors of self: The meaning of autobiography. New Jersey: Princeton University Press.

Orlikowski WJ and Iacono CS (2001) Research commentary: Desperately seeking the 'it' in IT research: A call to theorizing the IT artifact. Information Systems Research 12(2):121134. 
Ortner SB (1984) Theory in anthropology since the sixties. Comparative Studies in Society and History 26(1):126-66.

Palmer C Cooper J and Burns P (2010) Culture, identity, and belonging in the 'culinary underbelly'. International Journal of Culture, Tourism and Hospitality Research $4(4): 311-326$.

Peterson Y and Birg L (1988) Top hat: The chef as creative occupation. Free Inquiry in Creative Sociology 16(1):67-72.

Pratten JD (2003) The training and retention of chefs. International Journal of Contemporary Hospitality Management 15(4):237-242.

Rafaeli A and Vilnai-Yavetz I (2003) Discerning Organizational Boundaries through Physical Artefacts. In: Paulsen, N, Hernes T (eds) Managing Boundaries in Organizations: Multiple Perspectives. London: Palgrave, 188-210.

Reich A and Hager P (2014) Problematising practice, learning and change: Practice-theory perspectives on professional learning. Journal of Workplace Learning 26(6/7):418431.

Riemer J (1977) Becoming a journeyman electrician. Sociology of Work and Occupations $4(1): 87-98$

Robinson RNS (2008) Revisiting hospitality's marginal worker thesis: A mono-occupational perspective. International Journal of Hospitality Management 27(3):403-413.

Robinson RNS and Barron PE (2007) Developing a framework for understanding the impact of deskilling and standardisation on the turnover and attrition of chefs. International Journal of Hospitality Management 26(4):913-926.

Robinson RNS and Beesley LG (2010) Linkages between creativity and intention to quit: An occupational study of chefs. Tourism Management 31(6):765-776. 
Robinson RNS Solnet DJ and Breakey N (2014) A phenomenological approach to hospitality management research: Chefs' occupational commitment. International Journal of Hospitality Management 43:65-75.

Rowley G and Purcell K (2001) 'As cooks go, she went': Is labour churn inevitable? International Journal of Hospitality Management 20(2):163-185.

Salaman G (1974) Community and Occupation: An Exploration of Work/Leisure Relationships. Cambridge: Cambridge University Press.

Sandiford P and Seymour D (2007) The concept of occupational community revisited: Analytical and managerial implicationism face-to-face service occupations. Work Employment and Society 21(2):209-226.

Saunders KC (1981) Social Stigma of Occupations: The Lower Grade Worker in Service Organisations. Farnborough: Gower.

Schein E (2010) Organizational Culture and Leadership. San Francisco: Jossey-Bass.

Sennett R (2008) The Craftsman. New Haven: Yale University Press.

Sockrider GD (2005) History of the chefs uniform. Chefolio. Pflugerville, Texas: Escoffier Media.

Steiger TL (1993). Construction skill and skill construction. Work, Employment and Society, 7(4):535-560.

Steno AM and Friche N (2015) Celebrity chefs and masculinities among male cookery trainees in vocational education. Journal of Vocational Education \& Training 67(1):47-61.

Stewart H (2016) Being Japonaise: Understanding the Authentic Implications of Fusion Cuisine. CTSJ: Journal of Undergraduate Research 6(1):1-14.

Strangleman T (1999) The nostalgia of organisations and the organisation of nostalgia: Past and present in the contemporary railway industry. Sociology 33:725-46. 
Sullivan N (2012) The somatechnics of perception and the matter of the non/human: A critical response to the new materialism. European Journal of Women's Studies 19(3):299-313.

Tajfel H (1974) Social identity and intergroup behavior. Social Science Information 13(1):6593.

Taylor J and Forte J (2008) HACCP for the hospitality industry: The chefs' perspective. International Journal of Contemporary Hospitality Management 20(5):494.

Taylor S (2002) Overcoming aesthetic muteness: Researching organizational members' aesthetic experience. Human Relations 55(7):821-840.

Timo N (1993) Employment relations and labour markets in the tourism and hospitality industry. International Journal of Employment Studies 1(1):33-50.

Turner JC (1975) Social comparisons and social identity: Some prospects for inter-group behavior. European Journal of Social Psychology 5:5-34.

Wood RC (2000) Why are there so many celebrity chefs and cooks (and do we need them)? Culinary cultism and crassness on television and beyond. In Wood RC (ed) Strategic Questions in Food and Beverage Management. Oxford: Butterworth Heinemann, 129152.

Wood SM (1966) Uniform: Its significance as a factor in role-relationships. The Sociological Review 14(2):139-151.

Yanow D (2006) Studying Physical Artefacts: An Interpretive Approach. In Rafaeli A, Pratt, M (eds) Artefacts and Organizations: Beyond Mere Symbolism. Mahwah, NJ: Lawrence Erlbaum Associates, 41-60.

Zopiatis A (2010) Is it art or science? Chef's competencies for success. International Journal of Hospitality Management 29(3):459-467. 